\title{
UN ANÁLISIS DE LAS CONCEPCIONES ACERCA DE LA NATURALEZA DEL CONOCIMIENTO CIENTÍFICO DE LOS PROFESORES PORTUGUESES DE LA ENSEÑANZA SECUNDARIA
}

\author{
PRAIA, J. ${ }^{1}$ y CACHAPUZ,.$^{2}$ \\ 1 Facultade de Ciências da Universidade do Porto, 4000 Porto, Portugal. \\ 2 Secção Autónoma de Didáctica e Tecnologia Educativa da Universidade de Aveiro, \\ 3800 Aveiro, Portugal.
}

\section{SUMMARY}

Secondary science teachers play an important role in forming the imagt of science that is held by their pupils. However, research suggests that quite often science teachers' conceptions of the nature of scientific knowledge are little better that of their students. In Portugal, there are no research studies which may help to characterise science teacher's epistemological views in order to design appropriate training courses. 'This study aims (i) to diagnose what conceptions (empirist/rationalistic) are held by Portuguese secondary science teacliers concerning the relationship between theory and observation and also about the called scientific method (ii) to analyse the relationship between such conceptions, and the variables subject matter taught and professional experience. Basic data was generated from responses to a questionnaire (multiple choice questions) given by a representative sarnple of 464 science teachers. The results showed the predominance of empirist views (nearly $2 / 3$ of the sample) about the two aspects investigated. Empirist views seem to be independent of the teaching subject and professional experietice. The need for adequate training courses is discussed and suggestions concerning their design are proposed.

\section{INTRODUÇÃO}

A imagem đe ciência tida pelos alunos depende em boa medida do que thes é proporcionado pelos seus profes. sores de ciências. É assim compreensível o crescente interesse da investigação educacional pelo ensino da ciência dum ponto de vista epistemológico. Gallagher (1991) tem centrado a sua atenção na perspectiva de ciência que vai sendo passada aos alunos, na natureza da ciência tida pelos professores e na forma como ela influencia as suas práticas de ensino. Outros investigadores (Phillips 1985, Luken 1988) tem estado mais preocupados com a existência ou não de um método cientiffico, com a questão de saber se ele pode ser ensina* do e ainda com a forma de o ensinar. Vai hoje havendo evidências claras de que as concepções dos professores àcerca da natureza da ciência e do conhecimento científico e do que é o método influencia a forma de abordar um determinado conteúdo e portanto a imagem da ciência dada ao aluno. É nesta linha que King (199I) afirma "...é claro que o desconhecimento da história e da filosofia da ciéncia afecta negativamente o ensino da ciência". $\mathrm{Na}$ opin ão de Summers (1982), deve aprofundar-se o debate àcerca do papel desempenhado pela epistemologia das ciências naturais na formação dos professores. Este projecto parece ser de grande actualidade, já que frequentemente as concepçōes dos professores àcerca da natureza da ciência pouco diferem das dos seus alunos (Carey and Stauss 1970, Billeh and Malik 1977).

As conce:pçöes dos professores parecem ser maioritariamente dominadas por uma perspectiva empirista-indutivista àcerca do conhecimento científico (Cawthorn and Rowell 1978, Novak 1977, Hodson 1985) o qual, de acordo com este ponto de vista, radicaria fundamentalmente no papel da observação. Os factos científicos dariam significado à teoria e a observação é tida como a etapa meís importante do método científico. 
A nível do ensino, uma perspectiva empirista do conhecimento científico pode fazer crer aos alunos que se a observação meticulosa for seguida a aprendizagem de conceitos é algo (inquestionaveimente) adquirido. Daí a ênfase posta no trabalho experimental, com as caracte. rísticas referidas, bem como na tão divulgada "aprendizagem por descoberta". Como consequencia directa os alunos podem não se aperceber do carácter problemático do conhecimento científico. As correntes contemporâneas da epistemologia (por exemplo, Bachelard, Popper, Kuhn...) defendem uma concepçāo mais racionalista do conhecimento científico segundo a qual o conhecimento é construido com base em teorias que orientam a observaçāo, por outras palavras, uma observação dependente da teoria. Para estes filósofos da ciência o método científico não é entendido como uma sucessão linear de etapas mas antes um processo conducente à elaboração de ideias sucessivamente mais complexas. Popper, por exemplo, considera o método científico como a prossecução crítica do método da "tentativa e erro". Ao nível do ensino, a perspectiva racionalista defende ser o aluno quem tem a responsabilidade de construir (reconstruir) o seu proprio cohecimento. $O$ professor tem um papel importante como mediador entre o conhecimento científico e o conhecimento do aluno, pelo que a sua grande preocupação deve ser relativa à mudança conceptual e metodólogica (Gil 1992) e não à simples aquisição de conceitos. Os factos não podem ser abordados duma forma descontextualizada mas antes inseridos numa rede de razões, ou seja, discutidos com os alunos de forma a desenvolver neles o pensamento crítico, as capacidade de fundamentação e de argumentação.

Parece portanto poder afirmar-se que se quiser que uma perspectiva mais actual da natureza do conhecimento científico seja seguida pelos professores, eles terão de ser adequadamente preparados.

Em Portugal, a abordagem de questões da epistemologia não é frequente nos cursos de formação de professores e tambén não há estudos de investigação que sugiram formas adequadas de as planear.

Um possível ponto de partida é obter informação relativa às concepções dos professores àcerca da natureza do conhecimento científico relativamente à dimensão empirista/racionalista ${ }^{\dagger}$ Esta é a lógica deste estudo.

\section{OBJECTIVOS}

Tal como foi mencionado acima existem dois importantes aspectos epistemológicos que podem influenciar o ensino da ciência. Referimo-nos aos pontos de vista (perspectivas) dos professores àcerca (i) da relação entre teoria e observação e àcerca (ii) da natureza do método científico. Assim, os objectivos deste estudo são os seguintes:

- diagnosticar concep̧̧ões (empirista/racionalista) dos professores de ciências do ensino secundário em Portu. gal, no que respeita aos aspectos i) e ii) acima mencionados;
- analisar a relação entre aquelas concepçōes e as va. riáveis "disciplina que lecciona" e "experiência profissional".

Parece razoável esperar que as concepções dominantes dos professores de Ciências em Portugal, àcerca da natureza do conhecimento científico, não sejam muito diferentes das perspectivas dominantes dos seus colegas de outros países. Isto significa que podemos admitir a hipótese da dominância de concepções empiristas-indutivistas entre os professores envolvidos neste estudo (independentemente da area em que trabalham e da experiência profissional), visto que em Portugal a nivel da formação (inicial e contínua) é quase inexistente a formação e a reflexão epistemológicas, em particular com incidências no saber e no saber-fazer didácticos.

\section{METODOLOGIA}

Foi enviado um questionário a uma amostra aleatória de 1749 professores đe ciências do ensino secundário, ou seja, $20 \%$ da população para um total de 406 escolas de todo o País. A amostra foi estratificada de acordo com a disciplina leccionada, respeitando a representatividade da área no âmbito dos ensinos básico e secundário (Físico/Químicas; Geografia; Biologia/Ciências da Terra) e a experiência profissional ( $\mathrm{n}^{\circ}$ de anos de ensino). Uma amostra representativa de $\mathrm{N}=464$ professores de ciências foi obtida (respondentes) da amostra original para análise de dois aspectos aqui estudados. O questionário consistia em três partes distintas. A primeira parte (tratava de informaçäo geral àcerca de aspectos da sua formação académica e profíssional; a segunda parte pedia aos professores informação específica àcerca das suas experiências no campo epistemológico; a última parte do questionário (seis perguntas de escolha múltipla) teve em vista saber dos conhecimentos dos professores àcerca de questões de natureza epistemológica (no seu ensino). Cada uma destas seis questôes tinha quatro itens alternativos (colocados aleatoriamente): dois itens reflectiam diferentes pontos de vista empiristas e outros dois reflectiam diferentes perspectivas racionalistas. Tal procedimento, visou alargar o espectro das possíveis escolhas. Aos professores era pedido que escolhessem 0 item que considerassem mais apropriado. Embora fosse permitido dar "outras" respostas, só raramente tal aconteceu. As questōes foram validadas de forma independente por um painel de quatro especialistas em educação em ciência, e algumas ligeiras alterações foram introduzidas após um estudo piloto. Neste artigo serão analisadas apenas duas das questões da terceira parte que se relacionam especificamente com os objectivos dos estu. do (vidé apêndice). As restantes questôes estavam ainda relacionadas com as concepções dos professores àcerca de outros aspectos curriculares (e.g. o ensino do método científico enquanto tópico independente ou não do ensino/aprendizagem) e os resultados obtidos serão discutidos num próximo artigo. Assume-se, naturalmente, que os professores inquiridos têm concepçōes àcerca dos aspectos que se pretendem investigar e que tais concepções são passíveis de identificaçāo com o instrumento usado. 


\section{RESULTADOS}

As respostas dadas aos itens de cada questão reflectindo perspectivas empiristas foram incluídas numa única metacategoria $E$, tendo o mesmo sido feito para as perspectivas racionalistas $\mathrm{R}$. (Ver apêndice: questões 1 e 2).

A análise global, referente a cada questão aponta para perspectivas empiristas predominantes quanto à relaçāo entre teoria e observação: Questão $1, \mathrm{E}=74.4 \%, \mathrm{R}=22.4 \%$, $3.2 \%$ de não respondentes e "outros", bem como quanto à natureza do método científico: Questão $2, \mathrm{E}=79.3 \%$, $\mathrm{R}=17.7 \%, 3.0 \%$ de nāo-respondentes e "outros" (em ambos os casos a diferença entre as percentagens é significativa a $\alpha=0.01$ ).

Os resultados sugerem (Quadro I) que as concepçōes empiristas dos professores são independentes $(\alpha=0.0 \mathrm{I})$ dos conteúdos que ensinam (Q1: $X^{2}=5.99$ e Q2: $X^{2}=1.71$, $\mathrm{df}=2, \alpha_{c}=9.21$ ).

Os valores mais baixos observados nos resultados das respostas dadas em ambas as questōes, quanto às perspectivas empiristas dos professores de Geografia, podem estar relaciondas com a natureza não experimental dos respectivos conteúdos relacionados principalmente com os aspectos humanos e sociais.

\section{Quadro I}

Respostas $(\%)$ referentes a perspectivas $E$ ou $R$ para diferentes áreas disciplinares.

\begin{tabular}{|c|c|c|c|c|}
\hline Qucstão & $\begin{array}{c}\text { Matéria de } \\
\text { Ensino }\end{array}$ & $\begin{array}{c}\text { Físical } \\
\text { Química }\end{array}$ & Geografia & $\begin{array}{c}\text { Biologia } \\
\text { Geologia }\end{array}$ \\
\hline \multirow{2}{*}{1} & $\mathrm{E}$ & 81.5 & 65.3 & 73.2 \\
\hline \multirow{2}{*}{2} & $\mathrm{R}$ & 16.5 & 29.8 & 23.8 \\
\cline { 2 - 5 } & $\mathrm{E}$ & 82.8 & 73.6 & 81.7 \\
\hline
\end{tabular}

A experiência profissional (Quadro 2) não parece uma variável discriminatória $(\alpha=0.01)$ entre as perspectivas empiristas e racionalistas dos professores (Q1: $\mathrm{X}^{2}=0.26$ e Q2: $X^{2}=3.41, d f=2, \alpha=9.21$ ). Na globalidade, parece que quer os professores jovens quer os mais "velhos" (com mais anos de serviço) partilham perspetivas "nai. ves" (ingénuas) sobre a natureza do conhecimento cien. tífico.

Os resultados obtidos neste estudo corroboram os referidos anteriormente relativos à formação de base epistemológica dos professores. Assim, estes resultados estão de acordo com os comentários que, frequentemente, se podem ouvir nas Escolas "o mais importante para os alunos é a observação" ou "digo sempre aos meus alunos para observarem os fenómenos". A insistência nestes argumentos empiristas pode impedir os professores de intencional e conscientemente usarem estratégias de ensino que podem promover e desenvolver o espírito crítico é o pensamento criativo, que devem ser dois objectivos chave na educação em ciência desde os anos iniciais de Escola até à Universidade.

Quadro 2

Respostas (\%) referentes a perspectivas $\mathrm{E}$ ou $\mathrm{R}$ e sua relação com a experiência profissional.

\begin{tabular}{|c|c|c|c|c|}
\hline Questão & $\begin{array}{c}N^{\circ} \text { de anos } \\
\text { de ensino }\end{array}$ & $0-4$ & $10-14$ & $20 \cdot 24$ \\
\hline \multirow{2}{*}{1} & $\mathrm{E}$ & 71.4 & 76.3 & 69.2 \\
\cline { 2 - 5 } & $\mathrm{R}$ & 23.5 & 23.7 & 28.2 \\
\hline \multirow{2}{*}{2} & $\mathrm{E}$ & 81.5 & 85.5 & 71.8 \\
\cline { 2 - 5 } & $\mathrm{R}$ & 14.0 & 11.9 & 25.7 \\
\hline
\end{tabular}

\section{CONCLUSÕESEIMPLICAÇÕESDOESTUDO}

Oresultado deste estudo, indica, globalmente, uma orientação dominante para concepçōes empiristas em relaçāo à natureza do conhecimento científico por parte dos professores portugueses de Ciência. Obviamente, as implicaçōes educacionais deste estudo não são as de rotular os professores como empiristas ou racionalistas mas salientar a necessidade de planear cursos de formação quer inicial quer contínua onde se trabalhem aspectos epistemológicos. Estes cursos de formação deverão ter em conta os contex tos de prática pedagógica, já que, por si só, um bom conhecimento epistemológico por parte do professor não garante uma adequada exploração por parte do professor. Não se trata, pois, de desenvolver cursos de epistemologia geral. Nestes cursos deverá, assim, ser dada oportunidade aos professores em formação de discutirem as suas práticas, ajudando-os a desenvolver uma progressiva conscencialização das concepções epistemológicas presentes nas suas estratégias de ensino (por exemplo, aquando do uso do trabalho laboratorial) $\mathrm{e}$ a introduzir as adequadas modificaçōes. É de salientar que a nível da formação, a nossa experiência e reflexăo pessoais dizem-nos que a vertente epistemológica deve ser inserida nos objectivos, nas estratégias e nas actividades a desenvolver, que deve ser evidenciada a partir de exemplos definidos, sempre que possivel mobilizados a partír da análise das próprias aulas. S 6 assim, podemos esperar efeitos benéficos e motivadores para uma formação inovadora e de mudança. Só assim, os professores poderão apresentar aos alunos uma imagem mais adequada de Ciência.

Este estudo, limitou-se à análise das concepções dos professores. Por isso mesmo, não deve ser entendido senão como um ponto de partida. É de importância vital saber mais sobre o modo como tais concepçōes epistemológicas afectam as práticas de ensino da Ciência e, 
simultaneamente, o modo como estas influenciam aquelas.

Nesta linha e centrando agora o estudo na sala de aula, já está a ser feito algum trabalho que será objecto de um próximo artigo.

\section{NOTA}

1 Ñao significa que se defenda o debate epistemológico em tomo da dicotomia empirismo/racionalismo, jáque se reconhecem as Iimitações e perigos deste reducionismo. Surge, neste contexto, apenas com fins didácticos.

\section{BIBLIOGRAFIA}

BILLEH, V.H. e MALIK, H.H., 1977. Development and application of a test on understanding the nature of science. Science Education, 61, pp. 559-571.

BRICKHOUSE, N., 1990. Teacher's beliefs about the nature of science and their relationship to class pratice. Journal of Teacher Education, 41(3), pp. 53-62.

CACHAPUZ, F. 1992. Filosofía da ciência e ensino da Química. Repensaro papel do trabalho experimental. Paper apresentado ao Congresso "Las Didácticas Específicas en la formación del profesorado", Julio, Santiago de Compostela.

CAREY, R.L. e STAUSS, N.G., 1970. An analysis of the understanding of the nature of science by prospective secondary science teachers. Science Education, 52, pp. 358-363.

CAWTHORN, E.R. e ROWELL, J.A., 1978. Epistemology and science education. Studies in Science Education, 5, pp. 31-59.

CLEMINSON, A., 1990. Establishing an epistemological base for science teaching in the light of contemporany of the nature of science and of how children learn science. Journal of Research in Science Teaching, 27(5), pp. 429-455.

DUSCHL, R. e GITOMER, D., 1991. EpistemologicaI perspectives on conceptual change: implications for educational practice. Journal of Research in Science Teaching, 28(9), pp. $839-858$.

FINLEY, F.N., 1983. Science process. Journal of Research in Science Teaching, 20, pp. 47-54.

GALLAGHER, J.J., 1991. Prospective and practising secondary school science teacher's knowledge and beliefs about the philosophy of science. Science Education, 75(1), pp. $121-133$.

GIL, D., 1986. La metodología científica y la enseñanza de las ciencias unas relaciones controvertidas. Enseñanza de las Ciencias, 4(2), pp. 111-121.

GIL, D., 1992. Contribución de la historia y filosofía de las ciencias a la transformacion de la Enseñanza de las Ciencias. International Conference on History of the Physical
Mathematical Sciences and Teaching of Sciences, Madrid, Sept.

HODSON, D., 1985. Philosophy of science, science and science education. Studies in Science Education, 12, pp. $25-27$

HODSON, D., 1992. Assessment of practical work: some considerations in philosophy of science. Science Education, 1(2), pp. 115-144.

LUKEN, J.D., 1988. The scientific method in biology. Journal of College Science Teaching, February, 247-278 and 326.

KING, B.B., 1991. Beginning teacher's knowledge of and attitudes toward history and philosophy of science. Science Education, 75(1), pp. 135-141.

KUHN, T.S., 1972. La structure des revolutions scientifiques. Paris: Flamarion ( $2^{2}$ ed.) (tradução da edição aumentada de 1970) (Obra original publicada em 1962).

MATTHEWS, M.R., 1992. History, philosophy and science teaching: the present rapprochement. Science Education, $1(1)$, pp. 11-48.

NOVAK, J.D., 1977. A theory of education, (Cornell Univ. Press:: Ithaca).

OPPENHEIM, A.N., 1966. Questionnaire design and attitude measurement. (Heinemann: London).

PHILLIPS, D.C., 1985. Can scientific method be taught? Journal of College Science Teaching, November, 95-101.

POPPER, K., 1969. Conjectures and refutations. (Routtedje and kegan Paul: London>.

SANTOS, M.E. e PRAIA, J., 1992. Percurso de mudança na Diđáctica das Ciências. Sua fundamentação epistemológica. In "Ensino das Ciênciase Formaçäode Professores", Projecto "Mutare" (Coordenação de F. Cachapuz), n ${ }^{\circ} \mathrm{I}$, Univ. de Aveiro.

SUMMERS, M.K., I982. Philosophy of science in the science teacher education curriculum. European Journal of Science Education, 41, pp. 19-27. 


\section{APÊNDICE}

\section{QUESTÃO 1}

Alguns professores ao reflectirem sobre o modo como ś produzido o conhecimento científico, situam-se em posições distintas acerca da relação entre a observação e a teoria em ciência.

Apresentam-se algumas possiveis posiçōes:

1.1. As teorias são induzidas das obșervações científicas realizadas pelos investigadores (E).

1.2. As observações científicas realizadas pelos investigadores têm na generalidade como suporte quadros interpretativos ( $R$ ).

1.3. As teorias que entram em conflito com as observações realizadas pelos investigadores não obrigam a tejeição imediata das primeiras (R).

1.4. As observações cientf́ficas são o ponto de partida para a elaboração pelos investigadores das teorias em ciência (E).

1.5. Outra.

\section{QUESTÃO 2}

É comum o método científico ser apresentado aos alunos em manuais escolares como um conjunto de etapas sequencialmente ordenadas.

Referimos 4 sequências frequentemente propostas:

2.I. Observação de factos, Elaboração da hipótese, Comprovação experimental da hipótese, Conclusōes, Generalização (E).

2.2. Conhecimentos teoricos, Delimitação do problema, Elaboraçăo de hipóteșes, Comprovação experimental de hipóteses, Novos problemas $(\mathrm{R})$.

2.3. Observação de factos, Situação-problema, Elaboração de hipóteses, Comprovação experimental de hipóteses, Conclusões, Generalização. (E).

2.4. Situação-problema, Elaboração de hipoteses, Comprovação experimental de hipóteses, Conclusōes, Generalização (R).

2.5. Outras.

(E) perspectiva empirista

(R) perspectiva racionalista 